\title{
O ESTUDO DO MEIO COMO RECURSO E COMO CONTEÚDO CURRICULAR: FORMAS DE ABORDAGEM E ESTRATÉgIAS PARA A PRÁTICA DOCENTE DO $1 "$ CICLO DO ENSINO BÁSICO
}

\author{
Maria do Nascimento Esteves Mateus*
}

Não há uma tradição com raizes antigas em Portugal de uma área curricular vocacionada para o estudo e compreensão da realidade envolvente, na perspectiva de uma intervenção social e cívica, a não ser no $1^{\circ}$ Ciclo do Ensino Básico ou na disciplina de Estudos Sociais, hoje novamente História e Geografia, no $2^{\circ}$ Ciclo do Ensino Básico.

Recentemente, o estudo da comunidade, do mejo físico e social, das características económicas, dos valores, crenças e tradições da sociedade local ou nacional são feitos, segundo ROLDÃO (1995) por alargamento progressivo partindo de realidades observadas e experienciadas no meio próximo, local privilegiado e ponto de partida obrigatório para a análise da realidade social e ambiental.

De acordo com a referida autora, há três linhas preponderantes na análise dos Estudos Sociais, com maior ou menor importância em diferentes fases, sendo, contudo, a tendência para interagirem e se integrarem.

Assim, os Estudos Sociais podem ser entendidos como preparação para a cidadania através da transmissão de valores de participação social e intervenção do cidadão na sua comunidade, área formativa defendendo que a escola, usando métodos transmissivos, é um agente de transformação da sociedade na via de uma maior justiça social. Podem ligar-se às respectivas disciplinas científicas, usando métodos de descoberta, de forma a promover a preparação para a cidadania pelo exercício da tomada de decisões, baseados nos conceitos, processos e estruturas das respectivas disciplinas científicas e podem ainda adoptar uma investigação reflexiva de forma a promover a preparação para a cidadania através do processo de investigação onde os conhecimentos resultam das necessidades que os cidadãos sentem para a tomada de decisões e resolução de problemas.

O Estudo do Meio apoia-se no princípio do desenvolvimento cognitivo de acordo com os diferentes estádios de raciocínio em que a criança se encontra no sentido de uma

\footnotetext{
* Escola Superior de Educação de Bragança.
}

melhor adaptação ao meio, no princípio sociológico que acentua o estudo do meio local como laboratório experimental de formas de intervenção na sociedade em que a criança está integrada; e o enfoque localista que defende o reforço das metodologias de aprendizagem por descoberta e por análise directa do real.

A compreensão do meio local consolida a identidade pessoal e social, na medida em que reforça sentimentos de identificação, de partilha e pertença o que permite aos alunos reconhecerem-se como elementos de variados agrupamentos sociais.

O programa de Estudo do Meio no $1^{\circ}$ Ciclo do Ensino Básico parte da exploração do meio próximo para o longínquo, no sentido espacial e progride do presente para o passado segundo o alargamento temporal. Parte do imediato, do visível, do próximo e ainda do próprio aluno para os outros e para a comunidade.

Contudo, é discutível o princípio do alargamento progressivo, pois, nem sempre o mais próximo é o mais aliciante e motivador para a criança dado esta viver interiormente combinando o que ouve com o que imagina $\mathrm{e}$ com o que the fornecem os meios de comunicação. O misterioso casa-se com o quotidiano através da ficção, o passado torna-se tão importante como o presente e a auto-análise é difícil dadas as características físicas ou de personalidade de cada um.

Quais são os saberes e a prática úteis a um aluno para controlar o ambiente natural e social que faz parte dơ seu quotidiano?

Será o meio factor de motivação natural para a criança? O conhecimento da realidade próxima é atractivo?

Como pensam as crianças? Segundo Piaget, a criança do $1^{\circ}$ Ciclo encontra-se, em ternos de desenvolvimento psicológico, no estádio operacional concreto, limitada ao próximo e directo observado e experienciado, excluindo o distante, o imaginado, o hipotético. Mas diversos estudos. segundo ROLDÃo (1995) têm questionado este esquema rigido, previsivel e invariante e apontam para a possibili- 
dade de um raciocínio hipotético-dedutivo desde que as situações sejam contextualizadas e humanizadas.

É preciso compreender o porquê, como é e como pode ser o meio na mente e na afectividade de uma criança. Esta perspectiva conduz ainda, segundo ROLDÃO (1995) a um enfoque auto-analítico, a nível físico e a nivel psicológico. Ou o assunto é familiar, rotina diária e por isso mesmo irrelevante e a repetição de uma evidência não produz ou produz pouca aprendizagem; ou tem implicações afectivas e criam-se situações constrangedoras e indesejáveis num equílibrio educativo. Cabe ao professor precisar a descrição/observação/classificação das realidades do mejo envolvente e levar à redescoberta da parte fascinante e estimulante que encerra o quotidiano.

O envolvimento afectivo da criança com o meio gera dificuldade de distanciamneto o que se traduz em dificuldades de análise. O meio faz parte das experiências afectivas a que a criança adere espontaneamente, sendo visto como rotina e não como objecto de estudo.

No dizer de MATEUS (1995, p. 55) “(...), o meio local e regional, segundo a opinião de TRIGO (1993) pode ser considerado como recurso, porque promove as aprendizagens através dos meios e das competências existentes no meio e como conteúdo curricular, porque pode promover aprendizagens sobre o meio e a partir do meio". LIMA (1993, p.4) cita "Para ZABALZA (1991) o meio, como ambiente sobre o qual e através do qual se aprende, engloba um conjunto de dados de diversa índole e natureza que interactuam entre si, criando um espaço específico no qual os homens constroem a dinâmica da sua existência. Considera ainda que o meio engloba vários espaços "o social que engloba (...) os mundos produtivos, das estruturas de poder e da tradição cultural; o território onde se concretiza o social através de estruturas sócio-culturais e geográficas com caracteristicas que lhe dão unidade; a comunidade com a sua cultura própria e o seu modo especifico de desenvolver essa cultura".

É preciso sensibilizar o aluno para a tomada de consciência de que as características do meio interagem com os indivíduos, condicionam as suas opções, enquadram as suas vivências e actividades e que o meio não tem paredes que separam os homens. O meio deve ser encarado como meio próximo, locus privilegiado de ponto de partida do estudo da realidade social e ambiental onde a criança vive e deve ser preparada pra compreender e intervir e meio no sentido plural dos meios com sentido Homem/Meio numa relação interactiva com implicações económicas e culturais dos indivíduos e das sociedades.
A filosofia metodológica do Estudo do Meio baseia-se numa aprendizagem activa da realidade com envolvimento cognitivo e afectivo na construção dos saberes, de forma a promover o desenvolvimento integral da pessoa e o desempenho consciente da cidadania.

É a diversidade de áreas temáticas proporcionadas pela realidade natural e social que permite a análise 2 reflexão de realidades sócio-naturais que permitem processos sócio-afectivos de identificação e de pertença necessários ao crescimento da pessoa como ser biológico, social e cultural.

O papel determinante no desempenho de competências para a cidadania é dado pelos conteúdos e pelas metodologias que desenvolvem a consciência cívica e as práticas da vivência democrática. O conhecimento/compreensão da realidade social leva o indivíduo a posicionar-se face aos contextos sociais, a ter deles uma visão crítica e reflexiva e uma atitude participativa leva à promoção de atitudes de respeito pela diversidade e pela partilha e regras sociais de convivência plural. A prática de metodologias activas de aprendizagem desenvolvem o espirito de entreajuda, de cooperação, de rigor de análise, de respeito pelas opiniões e de responsabilização. Assim, o aluno aprende a analisar situações com rigor crítico e objectividade. Identifica e rejvindica os seus direitos, assume deveres, respeita os direitos e opiniões dos outros, valoriza as diferenças, coopera, persiste face a fins visados, age de forma responsável.

O programa de Estudo do Meio no $1^{\circ}$ Ciclo do Ensino Básico (1990, pág. 67) pressupõe uma organização por alargamento progressivo ao defender que "o meio local, espaço vivido, deverá ser o objecto privilegiado de uma aprendizagem metódica e sistemática da criança já que, nestas idades, o pensamento está voltado para a aprendizagem concreta", mas foca uma dependência local ao afirmar "mas a compreensão de realidades que elas não conhecem directamente só será possível a partir das referências que o conhecimento do meio próximo thes fornece". A observação do comportamento e interesses das crianças não parece confirmar esta visão um pouco redutora pois, concretas são para as crianças, todas as realidades vivenciadas, significativas, integradas e sobretudo humanizadas.

O carácter integrador dos temas procura evitar a abordagem disciplinarizante. Contudo, a organização por objectivos comportamentais ou operacionais e a estrutura em subtemas podem induzir a uma fragmentação. Cabe ao professor proporcionar a visão global e não atómica dos diferentes aspectos a abordar de acordo com o pensamento deste nivel etário, pois o referido Programa, na 
mesma página diz que "as crianças deste nível etário apercebem-se da realidade como um todo globalizante".

O programa em forma de objectivos operacionais faz com que os conteúdos apareçam integrados em forma de objectivos comportamentais ou operacionais, ou seja em termos de comportamentos ou resultados observáveis (descrever, enumerar, observar, reconhecer, identificar, construir...). A intenção é a de objectivar de forma rigorosa o tipo de resultados pretendidos sobre um dado conteúdo, dando importância ao observável, ao resultado, à avaliação em conformidade com o nível de objectivos definidos. É uma visão mecanicista da aprendizagem em que se promovem estratégias visando um produto final com base nas metodologias de treino, em que a preocupação se centra no sucesso como consecução dos objectivos e com actividades de remediação para fazer face às dificuldades. Assegura aos professores maior rigor no aprofundamento dos diferentes conteúdos, mas leva à fragmentação dos temas, a uma leitura não global, pelo que o professor deve promover una articulação vertical e horizontal.

Numa articulação horizontal há a preocupação de combinar e integrar os conteúdos do mesmo ano de escolaridade relativos a diferentes temas ou mesmo diferentes blocos e usar uma estratégia interdisciplinar, usando a descrição de uma situação, uma narrativa, um problema, um projecto, que proporcione a compreensão das interligações de diferentes áreas do saber e o aprofundamento de um tema em diferentes vertentes.

Numa articulação vertical a progressão dos conteúdos é feita ao longo dos quatro anos de escolaridade, em que BRUNER (1960) sugere a "aprendizagem em espiral" pois o mesmo conteúdo repetido em anos sucessivos implica uma abordagem mais alargada, o retomar de conhecimentos já adquiridos, a incorporação de novos conceitos, sem prescindir de um traballo de integração horizontal.

Consultando ainda o Programa do $1^{\circ}$ Ciclo (1990, p.67) "Todas as crianças possuem um conjunto de experiências e saberes que foram acumulando ao longo da sua vida, no contacto com o meio que as rodeia. Cabe à escola valorizar, reforçar, ampliar e iniciar a sistematização dessas experiências e saberes, de modo a permitir aos alunos a realização de aprendizagens posteriores mais complexas". Tal pressupõe que as crianças trazem saberes e experiências. São rigorosos e cientificos, baseados no senso comum, ou na adesão afectiva?

Segundo MONiz doS SANTOS (1991), trata-se de ter conta essas concepçōes alternativas e organizar estratégias de mudança conceptual para reconstruir novos conhecimentos. Nem todas as experiências resultam da vivência e aprendizagem do meio. Há vivências afectivas, subjectivas, cognitivas e emocionais. Cabe ao professor gerir as representações afectivas das realidades presentes ou imaginadas, os constrangimentos e gostos próprios, os conflitos e os interesses de cada um, não descurando as cargas sócio-culturais diversas pois têm uma grande importância quando confrontadas com a escola formal.

O mesmo programa (p.68) refere que "Os professores deverão recriar o programa, de modo a atender aos diversificados pontos de partida e ritmos de aprendizagem dos alunos" e que "Não é necessário que todos os alunos tenham de percorrer os mesmos caminhos", o que conduz a pensar nos ritmos e nas diferenças culturais e étnicas. Cada vez mais a escola se torna multicultural, os espaços são cada vez mais abrangentes. Todos conhecemos os fenómenos de migração em busca de trabalho e melhor nível de vida, a mobilidade de populações de etnia e culturas próprias como o povo cigano, o que torna necessária a diversificação ao nível das estratégias para a integração harmoniosa da diversidade étnica e cultural na defesa do direito à educação e ao sucesso educativo.

Impõe-se o respeito por essas experiências e saberes, o reconhecimento dos costumes, das tradições históricas, da matriz cultural de origem. Impõe-se partir do saber onde o aluno se encontra para o conhecimento de novas realidades, combater o fosso aluno-escola, adequar as aprendizagens às necessidades de cada um de forma a combater as assimetrias sociais discriminatórias.

A preocupação do Programa de Estudo do Meio com a formação pessoal e śocial dos alunos está presente na Área-Escola, na alternativa à Moral e Religião Católica ou outras confissões; nas actividades facultativas de complemento curricular e em todas as componentes e áreas curriculares.

As práticas docentes devem ser adequadas ao modo de pensamento das criancas, simples, aproveitando o potencial imaginativo e criativo; combinando afectividade e conhecimento, explorando a realidade próxima em termos de descoberta. Devem ser aprendizagens significativas, onde a tarefa a executar e o tipo de interesses pessoais joguem de forma objectiva, formativa e informativa.

ROLDÃO (1995) sugere algumas estratégias a serem utilizadas no sentido de tornar eficaz a aprendizagem.

A estratégia "Humanização e personalização dos conteúdos" é global, podendo ser para todos os temas mas para niveis etários baixos em que as referências afectivas e cognitivas se situam no domínio das vivências e experiências pessoais. A contextualização da actividade deve ser feita em termos de humanização da actividade a desenvolver. Personalizar os conteúdos significa criar 
contextos sentidos e vividos, levantar questōes/problemas que levem à procura de soluções com significado para as pessoas envolvidas.

A estratégia "Resolução de Problemas" apoia-se no ensino activo. Só o ensino problematizador desenvolve o pensamento reflexivo. Os problemas ou sâo empíricos (suscitando o levantamento de hipóteses...) ou de natureza teórica (conceitos de senso comum ou interrogações a partir de realidades conhecidas). Acredita no poder da ciência como factor de melloria dos problemas sociais, apoia-se em justificações de natureza pedagógica, valoriza a descoberta e problematiza a realidade. Segundo VILARJNHO (1983), o problema deve ser real, significativo, proporcionar uma investigação realizada pelos próprios alunos de forma reflexiva, sentido crítico e rigor, ser sentido por todos os alunos e não só pelo professor. As etapas de desenvolvimento passam por identificar, situar e definir o problema, formular hipóteses de explicação ou soluções possíveis, analisar ou verificar experimentalmente cada hipótese, rejejtar as soluções insatisfatórias, aceitar as mais adequadas, ou retomar a fase de formulação de novas hipóteses explicativas e seguintes, caso nenhuma se comprove.

A estratégia "Mudança conceptual a partir de concepções alternativas" dos alunos que são construídas a partir do senso comum ou da vivência empírica (o sol gira à volta da terra, a Terra é plana, a Lua tapa o sol durante a noite). A não consideração delas pelo professor pode dificultar ou inviabilizar a aquisição de conhecimentos científicos porque o aluno acredita nelas. Há que desmontar as concepções que os alunos têm como verdadeiras e perante a sua insatisfação colocá-los perante conceitos científicos fundamentados, com utilidade e aplicabilidade. A desmontagem é um processo de catarsismo pois visa a des-construção. O desenvolvimento, segundo MONIZ DOS SANTOS (1991), passa pela introdução que desencadeia o interesse; a identificação/clarificação das concepções alternativas para levar os alunos a clarificar e justificar procurando razões; a exploração das concepções alternativas em que situações criadas pelos alunos testam as suas concepções e descobrem a ambiguidade e a dúvida; a discussâo das concepções alternativas em que se discute o conflito cognitivo, toma o aluno insatisfeito e reconhece o novo conceito; a reflexão em que se analisa a evolução cognitiva consciencializando-o da evolução, da mudança e das conclusões; a aplicação a novas realidades e à própria vida quotidiana.
A estratégia "Organização de um projecto investigativo" baseia-se na metodologia do trabalho de projecto mas em projectos centrados em temas integradores de experiências vividas, de projectos centrados na escola ou na comunidade, de projectos centrados na construção de um produto final (exposição temática). É um projecto interdisciplinar com autonomia e flexibilidade na gestão individual das tarefas. Parte de um interesse comum, partilhado como necessidade ou problema, pela definição de objectivos, dos processos e do produto final, prevê formas de avaliação contínua das tarefas a desenvolver ao longo do projecto $\mathrm{e}$ os alunos investigam autonomamente embora orientados pelo professor.

A estratégia "O uso da narrativa" considera esta como estrutura organizativa de conteúdos que prende afectivamente o aluno. As histórias têm atravessado épocas e culturas e são instrumentos poderosos de transmissão de ideias, crenças, costumes, valores e mensagens ideológicas, políticas, religiosas ...

A história, seja fábula, romance, mito, ou outra, é um veículo cultural e o que a caracteriza é o formato narrativo que pode começar pela existência de um conflito ou tensão desencadeadores da acçâo, protagonismo e personificação do conflito em personagens, indivíduos con características pessoais bem marcadas; desenvolvimento da acção com sequência de eventos narrados em pormenor; conclusão que se traduz na resolução ou ruptura do conflito ou tensão sendo estes o fio condutor da narrativa.

Podem aparecer, segundo ROLDÃo (1995) dois tipos de "Uso da narrativa". Na perspectiva de Kieran Egan a criança interpreta o mundo em termos de conflitos entre conceitos opostos - felicidade-tristeza, coragem-medo, segurança-perigo - que são categorias abstractas correspondentes às suas experiências interiores. A organização dos conteúdos deverá ser de acordo com esses conflitos binários.

Na perspectiva de Letschert a abordagem da estrutura narrativa pode ser mais desenvolvida e enquadrar os conteúdos da aprendizagem. Consiste na desmontagem do tópico da narrativa escolhido em episódios mais curtos. Em cada episódio há um conjunto de questões a investigar; conceitos-chave a apreender; actividades e tarefas que os alunos irão desenvolver para dar resposta às questões e adquirirem conceitos; modo de organização do trabalho na aula; recursos necessários e modos de avaliação. 


\section{Bibliografia}

BRuner, J. (1960) - The Process of Education. Cambridge MA Harvard University Press.

EGAN, K. (1994) - O Uso da Narrativa como Técnica de Ensino. (Trad. M. C. Roldão). Lisboa. Publicações Dom Quixote.

LiMA. M. J. (1993) - "As Componentes Regionais e Locais do Curriculo - Un Instrumento para a Consecução dos Objectivos do PEPT". Em A Escola é para Todos. Caderno $\mathrm{n}^{\circ}$ 2. Lisboa, Editorial do Ministerio da Educação. pp. 3-4.

MAteus. M. N. (1995) - Area-Escoln, Educação Ambiental e Práticas Pedagógicas Inovadoras. Tese de Mestrado em Extensão e Desenvolvimento Rural. Vila Real.

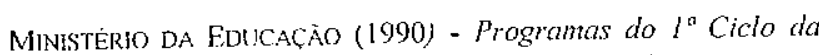
Escolaridade Bárica. Lisboa. Ministério da Educaçâo.
MONI7 DOS SANTOS. M. E. (1991) - Hudança Conceptual ha Sala de Aula - um desafo pedagógico. Lisboa. Livros Horizonte.

ROLDÃo. M. C. (1994) - O pensamento Concreto da Crianç Lima Perspectiva a Questionar no Curriculo. Lisboi. Instituto de Inovação Educacional.

ROLdÀO. M. C. (1995) - O Estudo do Meio no $l^{\circ}$ Cíclo Fundamentos e Esiratégias. Lisboa. Texto Editora.

TRIGO, M. M. (1993) - "As Componentes Regionais e Locais do Currículo ou o Meio como Conteúdo Curricular". En A Escola é para Todos. Caderno $\mathrm{n}^{\circ} 2$. Lisboa. Editorial do Ministério da Educação, p. 2.

VIl_ARINHO, L. (1983) - Didactica - Temas Seleccionados. Rio de Janeiro. Livros Técnicos e Científicos Editora. 